\title{
Role Conflict, Role Balance and Affect: A Model of Well-being of the Working Student
}

\author{
Janet A. Lenaghan and Kaushik Sengupta \\ Hofstra University
}

\begin{abstract}
A conceptual model of the working college students' well-being was developed and tested. This study extends existing research and investigated the process by which rolebalance, role-conflict and affect are associated with a student's well-being. Data were obtained from a sample of 320 full-time college students (18-23 years old) who had either a full and a part-time paid job. The model was tested using structural equation modeling. Results supported the proposed conceptual model as well as the enrichment and depletion arguments of students' engagement in multiple roles and their well-being.
\end{abstract}

\section{Introduction}

In the last several years, colleges and universities have been intensely looking at selection and retention issues among students. One of the main concerns in the recruitment and retention of students is the escalating cost of tuition. In order to meet the increasing tuition costs, many students have to be employed in a full-time or parttime job in order to meet the financial needs. This is further prompted by the fact that many parents can no longer support or bear the full financial costs of a college education. In addition, the limited number of scholarships is highly competitive and student loans are not sufficient to cover all the expenses. The result is an increased prevalence of students who are employed during their college careers. As students increasingly engage in paid work, college administrators and educators are concerned that a student's motivation to engage in schoolwork will wane. The resulting role conflict between school and work can be a source of stress, absenteeism and even turnover.

Researchers have always been interested in studying the effect of multiple roles and interrole conflict. Much has been written on role conflict in the work/family literature (Greenhaus and Powell, 2006; Barnett and Hyde, 2001; Greenhaus and Parasuraman, 1986). However, few studies have focused on the student/work relationship and interrole conflict. Buda and Lenaghan (2005) conducted a study that directly investigated this relationship. The findings in their study indicated that the work/student relationship produced strain or stress that negatively affected well-being. These findings corresponded to that of Rothbard (2001) where he examined the relationship between work and family. In addition, the findings also suggested that students may find work as both instrumental and emotional in achieving their goal of acquiring a college education. Incidentally, these findings also paralleled the study of Lucas and Lamont (1998) where they investigated the effects of combining work and study in university students. They concluded that economic reasons drive a student to work and this is 
often necessary but working is also an emotional experience that aids in the social development of the students.

Buda and Lenaghan (2005) also found that role-balance was an important issue for college students. Students perceived greater role-conflict when there was a lack of rolebalance in their lives. However, there was no relationship found between role-balance and well-being which was contrary to the findings in the work/family literature. It was perceived that an emotional construct such as affect could be moderating this relationship in students (Buda and Lenaghan, 2005). In this research we investigated the work/student relationship and developed a path model of the working student's wellbeing using structural equations.

\section{Theoretical Background}

The effect of a student's employment on schoolwork is an important question for college administrators. The fear that engagement in work is achieved at the expense of school work must be investigated. Researchers have posited two competing arguments, depletion and enrichment, to address the dynamics of these multiple roles.

\section{Depletion Argument}

The depletion argument of inter-role conflict, according to Kahn, Wolfe, Quinn, Snoek and Rosenthal (1964, p.19), is defined as the "simultaneous occurrence of two (or more) sets of pressures such that compliance with one would make more difficult compliance with another." Opposing pressures arise from engaging in multiple roles, and these pressures can be incompatible by requiring different roles to compete for a person's limited time resources as well as the strains associated with one or more roles (Kopelman, Greenhaus and Connolly, 1983; Rothbard, 2001).

Multiple roles could compete for a person's time where time spent on activities within one role could not be devoted to activities within another role (Greenhaus and Beutell, 1985). As Lobel (1991) discussed, this utilitarian view of role investment placed one role against another thereby creating a win-loss equation - time invested in one role depletes time devoted to another. This could occur in two different ways. First, time pressures associated with one role may make it physically impossible to comply with expectations from another role. Second, time pressures may also produce a preoccupation with one role while attempting to meet the demands of another role (Bartolome and Evans, 1979). According to Greenhaus and Beutell (1985), role demands would not be met if a person was physically absent from a role or was mentally preoccupied with another role. In addition, it was also suggested that people not only sought pleasure but also invested time coping with role displeasure (Rothbard and Edwards, 2003). Therefore, the depletion argument was based on work-family research that examined the conflict between work and family roles in an individual's life. Individuals' engagement in multiple roles in response to role demands caused strain. 
Strain, often conceptualized as a negative emotional response to stress, could result in depression or negative affect (Rothbard, 2001). In fact, Stoeva, Chiu and Greenhaus (2002) found that negative affect indirectly affected work-family conflict through its effect on job stress and indirectly affected family-work conflict through its effect on family stress. Netemeyer, Boles and McMurrian (1996) suggested that work-family conflict was negatively associated with turnover intentions and physical symptoms. Greenhaus, Allen and Spector (2006) found significant health consequences of work-family conflict. Frone (2003) linked work-family conflict to psychiatric and substance abuse disorders. In addition, Bruck and Allen (2003) found that negative affect was most consistently related to various types of conflict. If one transferred the depletion argument to the work-student domain, then stressful experiences at work could evoke negative affect that was then transported to the school setting (Repetti, 1987).

Strain based conflict exists when strain in one role affects performance in another role due to the incompatibility between the roles (Pleck, Staines and Lang, 1980). According to Edwards and Rothbard (2000) strain based conflict could occur when participation in a role produced strain that hampered role performance in another role. According to this definition, any work or school role that produced strain contributes to a work-school conflict in college students. Also, there was some evidence that a college student's expectations played a role in work-school conflict. Barnett, Gareis, James and Steele (2003) found that college seniors whose mothers worked outside of the home while the seniors were children would express less concern about career-marriage conflict than seniors with stay-at-home mothers. In addition, the expectations of college seniors about the timing of their marriages and childbearing related to their concerns about career-marriage conflict (Barnett, Marshall and Pleck, 1992). The role conflict here came from within the individual in the form of strain or stress that was internal, often described as feelings of well-being.

\section{Enrichment Argument}

The enrichment process takes a positive view of multiple roles. It sees the available supply of energy as abundant and expandable. Some roles may be performed without any net energy loss and some roles may even create additional energy use in that role or other roles (Goode, 1960). Marks (1977) enumerated the following four points on the enrichment process:

(1) Rather than allowing energy to simply flow out mechanically in response to role demands, individuals could decide how to use their energy and in which role.

(2) People withhold the full flow of energy into a given role thereby freeing energy for other roles.

(3) Feelings of energy loss are more of a function of role balance.

(4) In the long run people have ample energy for all of their roles regardless of energy expenditures. 
The enrichment process as postulated by Marks (1977), suggested that as an individual increased his/her number of roles there was a gain or benefit from them through enrichment rather than a loss through depletion. In addition, having multiple roles was gratifying since the benefits of multiple roles outweighed the costs (Rothbard, 2001). Barnett and Hyde (2001) presented the expansionist hypothesis of this argument suggesting that the advantages of multiple roles far exceed the detrimental effects and yield an overall positive influence on one's well-being. They concluded that both men and women benefit by engaging in multiple roles in terms of their mental health. Other researchers have supported the positive affect of multiple roles and advantageous relationship between work and family. Many explored the positive spillover of the two domains (Grzywacz, Almeida and McDonald, 2002; Hammer, Cullen, Caubet, Johnson, Neal and Sinclair, 2002; Hanson, Colton and Hammer, 2003; Voydanoff, 2001) while others have viewed the relationship as one of enhancement (Ruderman, Ohlott, Panzer and King, 2002) and facilitation (Frone, 2003).

Marks and MacDermid (1996) demonstrated that people with more balanced role systems reported less strain, more role-ease, greater well-being and more positive role specific experiences than people with less balanced role systems. Role balance, defined as a general orientation across roles, is both a behavioral pattern of acting across roles in a certain way and a cognitive affect pattern of organizing one's inner life (Marks and MacDermid, 1996). Two components of role-balance were of particular interest in our study: role-overload and role-ease. Role-overload was used as a measure of role-strain. People with more balanced role systems would report less rolestrain, more role-ease and usually greater feeling of well-being (Marks and MacDermid, 1996). Role-ease was used to measure any perceived ease in carrying out one's role performances. Role-overload and role-ease required separate conceptualizations or measurement (Marks and MacDermid, 1996). Just as health and well-being are different than the absence of disease, role-ease could also have some unique properties and characteristics and it could coexist with a certain amount of role-overload or it might begin only when there was no role overload. Nevertheless, separate concepts of strain and ease were needed to measure role-balance (Marks and MacDermid, 1996).

Figure 1

Conceptual Model for the Process of Wellbeing

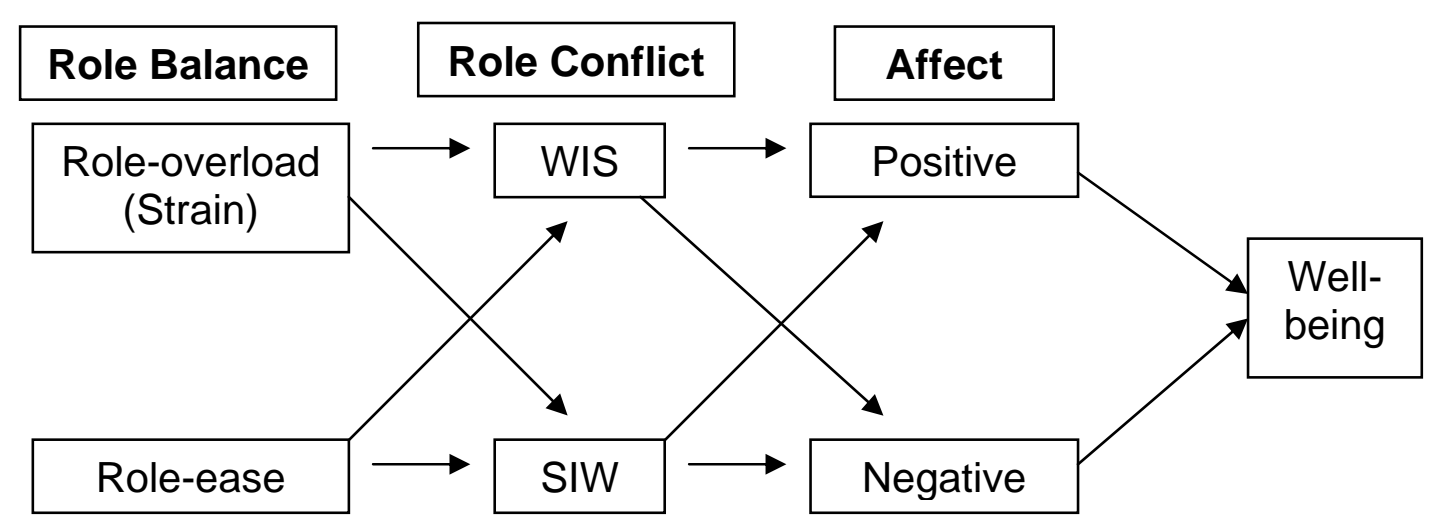




\section{Conceptual Model of Well-being}

Drawing upon the above literature, our model proposed that a student's well-being was determined by three exogenous variables: Role Balance, Role Conflict and Affect. These three variables were divided into two paths, one representing the enrichment argument and the other the depletion argument. The model is shown in Figure 1.

\section{$\underline{\text { Role Balance }}$}

The first exogenous variable, role-balance, was based on a student's experience while engaging in multiple roles. Since role-balance seemed to neutralize the effects of rolestrain, we used two components of role-balance, Role-Overload (depletion argument) and Role-Ease (enrichment argument). Using these two measures allowed us to test the depletion and enrichment arguments without too much ambiguity. When scores on Role-Overload were low it was interpreted as Role-Ease. Correspondingly, when scores on Role-Ease were low it was viewed as Role-Overload. It was expected that the two scores would be correlated. Since we did not know when role- overload ended and roleease began, it became necessary to measure both conceptually to get a sense of rolebalance because of the theory that role-balance generated role-ease and the lack of role-balance generated role-strain (overload) as systematic outcomes.

\section{$\underline{\text { Role Conflict }}$}

Role conflict was defined as the extent to which a person experienced pressures within one role that were incompatible with pressures within another role (Kopelman, et al., 1983). Role conflict could arise from several different sources. For example, it was possible that requirements for different roles might compete for a person's limited time resources or it could occur due to various strains associated with multiple roles. Therefore, role-conflict would follow temporally role-balance in the work/college student relationship and, in our conceptual model, we evaluated role conflict as conflict arising from either work interfering with school (WIS) or school interfering with work (SIW). Extant research clearly placed role-conflict after role-overload or strain in the temporal sequence. Since previous research had determined that work was instrumental in achieving a college degree, one would expect WIS to be the type of conflict that would result from experiencing role-overload (strain). However, inter-role conflict could also be experienced by SIW resulting from role-ease lending support for the enrichment argument. It thus became necessary to measure both WIS and SIW in this study.

\section{$\underline{\text { Affect }}$}

Earlier studies had examined the relationship between well-being and positive and negative affects (Burke, Brief and George, 1993; Watson, Clark and Tellegen, 1988). The results supported the notion that individuals with a more positive personality trait experienced less stress than those with a negative trait. Stated differently, research had 
shown a positive correlation between negative affect and stress (Chen and Spector, 1991). In general, positive and negative affects represented predispositions to experience the corresponding mood factor (Tellegen, 1985).

Positive affect (PA) was characterized by an individual's feelings of energy, excitement, enthusiasm, attention and an overall sense of well-being (Watson, et al., 1988; George, 1989). These individuals thought and behaved in a manner supportive of positive emotions (Watson and Pennebaker, 1989) and they experienced intense and pleasant feelings. Individuals who scored low on positive affect had a diminished overall feeling of well-being but negative affect was not necessarily present. Rather, their moods were characterized by feelings that denoted both the absence of positive emotions as well as a lack of energy (Watson and Tellegen, 1985).

Negative affect (NA) referred to the tendency to experience intense unpleasant feelings. It is typically characterized by a general mood of distress, constituting states such as anger and depression, and a tendency to experience intense unpleasant feelings. High NA individuals were more introspective, dwelled on shortcomings and they generally focused on the negative side of things: the proverbial "glass-half-full" view of life (Watson and Pennebaker, 1989). Such individuals would perceive unexpected events as threats rather than opportunities. Thus, negative affect represented subjective differences in mood, temperament and cognitive orientation.

Students in multiple roles and experiencing either WIS or SIW conflict could have either positive or negative emotional responses. In this study, this emotional response was identified as affect. Past research suggested that positive and negative affect were not at opposite ends of the same variable but were actually independent of each other (Watson and Tellegen, 1985). The depletion and enrichment arguments were based on the assumption regarding an individual's emotional response (Rothbard, 2001). The depletion argument suggested that engagement in multiple roles increased the stress and strain associated with the roles and this lead to negative emotional responses (Kopelman, et al., 1983). On the other hand, the enrichment argument suggested that role engagement could provide an enriching experience because benefits such as role privileges, status and self-esteem accrued to those who engaged in multiple roles (Rothbard, 2001). In our conceptual model, we placed affect (both positive and negative affects) next in the temporal sequence leading to feelings of well-being. Extant research has established a strong relationship between affect and well-being and this allowed us to envision a conceptual path model linking role-balance, role-conflict and affect to wellbeing.

\section{Well-being}

The target or endogenous variable in our study was well-being. Researchers had developed models to predict how work and family influenced stress and well-being (Frone, Russell and Cooper, 1997; Greenhaus and Parasuraman, 1986; Higgins and Duxbury, 1992; Kopelman, et al., 1983; Martin and Schermerhorn, 1983; Parasuraman, Purohit, Godshalk and Beutell, 1996). Edwards and Rothbard (1999) studied how the 
cognitive appraisal process influenced stress. Buda and Lenaghan (2005) found time stressors related to the well-being of college students. Using the person-environment fit theory, Edwards and Rothbard (2000, p. 85) "examined how the comparison of work and family experiences to the person's values relates to stress and well being". They wanted to explore possible explanations for why different people in the same situation experienced different levels of stress.

Some models of work and family stress used individual differences as moderators of the effects of work and family experiences on well-being (Greenhaus and Parasuraman, 1986; Higgins, Duxbury and Irving, 1992; Martin and Schermerhorn, 1983; Parasuraman, et al., 1996). Friedman and Greenhaus (2000) argued that lack of time was not the major enemy of work-family conflict; rather it was the level of psychological interference of work into the family domain and of family concerns into the workplace that lead to conflict. Recent research had also associated personality variables and work-family conflict. Personality traits that have been studied with regards to its interaction on work-family conflict included aggressiveness (Lightdale and Prentice, 1994) and negative affectivity (Carlson, 1999, Bruck and Allen, 2003). In addition, several studies had found a positive relationship between Type A behavior and workfamily conflict (Burke, et al., 1979; Burke and Weir, 1980). Therefore, we had adequate reasons to believe that some, but not all of what was found in the work/family research on well-being, would transfer to the work/school domain.

\section{Research Hypotheses}

Based on the conceptual model suggested in Figure 1 and the above discussions, the following hypotheses are tested on two arguments, Enrichment and Depletion.

Enrichment Argument

The enrichment argument was built on the basis that an individual with positive attitudes towards multiple roles would experience role-ease, SIW and positive affect that would all lead to a positive association with well-being. Such an individual would actually relish the prospect of having multiple roles and he/she would see this as a net positive effect on his/her well-being. Accordingly, we had the following three hypotheses associated with the enrichment argument.

Hypothesis 1a ( $\mathrm{H} 1 \mathrm{a})$ : Role-ease will be positively associated with well-being

Hypothesis $1 \mathrm{~b}(\mathrm{H} 1 \mathrm{~b})$ : SIW will be positively associated with well-being.

Hypothesis 1c (H1c): Positive affect will be positively associated with well-being

\section{Depletion Argument}

The depletion argument would take the opposite view to the enrichment argument by postulating that conflicts due to multiple roles create a detrimental effect to a student's well-being. Feelings of role overload, work interfering with school and a negative affect 
would therefore be associated with well-being. Accordingly, we had the following three hypotheses associated with the depletion argument.

Hypothesis 2a ( $\mathrm{H} 2 \mathrm{a})$ : Role-overload will be negatively associated with well-being.

Hypothesis $2 b(\mathrm{H} 2 \mathrm{~b})$ : WIS will be negatively associated with well-being.

Hypothesis 2c $(\mathrm{H} 2 \mathrm{c})$ : Negative Affect will be negatively associated with well-being.

\section{Methodology}

\section{$\underline{\text { Participants }}$}

Respondents included students who participated in a Quality of Academic Life Study conducted at a major university in the North East U.S. A proportional random sample of classes was selected from each of the business departments in the School of Business. Students in each selected class were asked to volunteer to participate in the study. They were told that the study is part of a university-wide effort to assess the quality of academic life. Only volunteers who were currently working at least 20 hours per week were selected to participate. The sample consisted of 322 undergraduate students enrolled in a BBA program. Of the 322 students, 152 were male and 170 female; 297 single, 18 married, and 4 parents and 3 single parents. The average age of the sample was 22.72. There were 187 seniors, 104 juniors, 26 sophomores, and 5 freshmen in the sample; 264 of these students were full time and 58 were part-time. 65 lived on campus, 77 lived off campus and 180 lived at home. Of the 322, 114 were employed fulltime (35 hours or more) and 208 part-time.

\section{Procedure}

Since it was important to have working students in the study, data were collected at two different times in ten separate classes. Six administrations of the Quality of Academic Life Study were in day classes and four were in evening classes. There was no subject loss or attrition rate since it was a one-time collection. All participants were volunteers and received no incentives to participate. The participants were given instructions by the authors, which included guarantees of anonymity, the use of the scales, and instructions to return completed surveys to a specific student who would then insert the surveys in an envelope and seal it. The authors and the professors in the classes left the classroom after providing all the instructions leaving the students to complete the surveys. The length of time of administration of the survey was approximately 20-25 minutes.

\section{$\underline{\text { Measures }}$}

The General Well-Being Scale (GWB), developed for the National Center for Health Statistics, is a structured instrument for assessing self-representations of subjective well-being. (Dupuy, 1977) It is widely accepted and has been used in many recent 
studies to measure resiliency or hardiness (Svavarsdottir and Rayens, 2005; Karatzias, Chouliara, Power, and Swanson, 2006). Scale scores run from 14 (lowest well-being) to 134 (highest well being) for the 18 items as described by Fazio (1977). Scale norms were available from a sample of 79 male and 119 female students at the University of Wisconsin, Milwaukee, in a freshman psychology class (Fazio, 1977). Mean scores for the first 18 items of the schedule were 75 for men and 71 for women. (SD = 15 and 18 respectively). Internal consistency reliability (Cronbach's alpha) was .91 for men and .95 for women. The reliability and validity of the GWB scale has been supported in numerous studies (McDowell and Newell, 1987). The total score on the 18 item provides a measure of overall well-being. An example of an item from this scale is "Have you been under or felt you were under any strain, stress, or pressure (DURING THE PAST MONTH?)".

The two measures of role-balance, Role Overload and Role Ease, were measured on multi-item, 5-point Likert scales (Marks and MacDermid, 1996). The items asked the respondents to orient their responses to different nuances of the role-overload and roleease constructs. The scores on the constructs were determined by summing the scores on each item and then calculating the mean.

Role conflict was measured using a modified version of an instrument that measured work-family conflict developed by Kopelman, et al., (1983). The student role was substituted for references to the family role used in the original instrument. Three items assessed whether work interferes with being a student (WIS) and another three items assessed whether being a student interferes with work (SIW). Both scales used 5-point Likert scales with a reliability coefficient of 0.81 for WIS and 0.79 for SIW. The scale items are listed in Table 1.

Table 1

Items in the Role-Conflict Scale Role Conflict (WIS)

My family/friends dislike how often I am preoccupied with my work while I am at school

My work takes up time that I would like to spend with family and friends

After work I come to school too tired to do some of the things I like to do

\section{Role Conflict (SIW)}

My school life takes up time that I like to spend at work

My superiors and peers dislike how often I am preoccupied with my school life at work

My school demands are so great that it takes away from my work.

Positive and negative affect was measured by the PANAS instrument developed by Watson, et al. (1988). PANAS consisted of twenty words (10 positive and 10 negative items) that described different feelings and emotions. The respondents were asked to 
rate each word as to the extent of how they felt when they took the survey. The scale was a 5-point Likert scale with a reliability coefficient of 0.88 .

\section{$\underline{\text { Measurement Path Model }}$}

We estimated the hypothesized paths using LISREL8.30 (Joreskog and Sorbom, 1986). Input data for the model were the raw scores of the observed or manifest variables. The exogenous latent variables in the model were Role-Overload, Role-Ease, WIS, SIW, Positive Affect and Negative Affect. The endogenous latent variable was WellBeing. Recognizing that the measurement path analysis was a special case of structural equation modeling (SEM), it was decided to use SEM to develop the paths instead of the traditional regression analysis. Regression assumed that the manifest variables were measured without error and interpretation of results were assumed to be error free. In contrast, specification of measurement errors is an integral part of SEM and using LISREL to estimate the path parameters is a more robust method (Pedhazur and Schmelkin, 1991). To evaluate this model we performed goodness of fit tests to determine the fit of the model. The results are discussed next.

Table 2

Means, Standard Deviations and First Order Correlations of Variables in the Study

\begin{tabular}{|c|c|c|c|c|c|c|c|c|c|}
\hline \multicolumn{10}{|c|}{$(n=322)$} \\
\hline Variables & Mean & Sd. & $\begin{array}{l}\text { Well- } \\
\text { Being }\end{array}$ & $\begin{array}{c}\text { Role- } \\
\text { Overload }\end{array}$ & $\begin{array}{l}\text { Role- } \\
\text { Ease }\end{array}$ & WIS & SIW & $\begin{array}{l}\text { Pos. } \\
\text { Affect }\end{array}$ & $\begin{array}{l}\text { Neg. } \\
\text { Affect }\end{array}$ \\
\hline Well-being & 56.89 & 12.82 & .88 & & & & & & \\
\hline $\begin{array}{l}\text { Role- } \\
\text { Overload }\end{array}$ & 18.45 & 5.49 & $\begin{array}{l}.54 \\
(\star \star)\end{array}$ & .89 & & & & & \\
\hline $\begin{array}{l}\text { Role- } \\
\text { Ease }\end{array}$ & 14.88 & 4.15 & $\begin{array}{l}.43 \\
(* *)\end{array}$ & $\begin{array}{l}.60 \\
(\star \star)\end{array}$ & .82 & & & & \\
\hline WIS & 3.09 & 0.88 & $\begin{array}{l}.42 \\
(* *)\end{array}$ & $\begin{array}{l}.59 \\
(* *)\end{array}$ & $\begin{array}{l}.44 \\
(* *)\end{array}$ & .72 & & & \\
\hline SIW & 3.37 & 0.86 & $\begin{array}{l}.40 \\
(* *)\end{array}$ & $\begin{array}{l}.43 \\
(* *)\end{array}$ & .40 & $\begin{array}{l}.40 \\
(* *)\end{array}$ & .71 & & \\
\hline $\begin{array}{l}\text { Positive } \\
\text { Affect }\end{array}$ & 3.09 & 0.89 & $\begin{array}{l}.28 \\
(* *)\end{array}$ & .15 & $\begin{array}{l}.11 \\
(*)\end{array}$ & .09 & $\begin{array}{l}.21 \\
(* \star)\end{array}$ & .90 & \\
\hline $\begin{array}{l}\text { Negative } \\
\text { Affect }\end{array}$ & 1.73 & 0.78 & $\begin{array}{l}-.42 \\
(* *)\end{array}$ & $\begin{array}{l}-.27 \\
(* *)\end{array}$ & -.10 & $\begin{array}{l}-.19 \\
(\star \star)\end{array}$ & $\begin{array}{l}-.15 \\
(* \star)\end{array}$ & .09 & .80 \\
\hline
\end{tabular}

Note: Reliability coefficients (Bold) are placed in the diagonal; WIS $=$ Work Interferes with School; SIW = School Interferes with Work; ${ }^{\star *}=p<.01,{ }^{*}=p<.05$, (2-Tailed) 


\section{Results}

\section{Tests of Hypotheses}

Table 2 presents the means, standard deviations, reliability estimates and correlations among the latent variables of the path model. As shown in Table 2, the internal consistency reliability estimates for the latent variables were in acceptable ranges. An inspection of the total sample correlations showed bi-variate support for our hypothesized relationships for the enrichment argument and little support for the depletion model. Role-Ease, SIW, and Positive Affect were positively and significantly related to Well-Being $(p .<.01)$, indicating that engaging in multiple roles was beneficial to college students. Role-Overload and WIS were also significantly related to WellBeing $(p .<.01)$. However, the associations were in the opposite direction of the hypotheses. Negative affect $(r=-.42, p .<.01)$ was negatively related to well-being as hypothesized. Based on the correlations, there was strong support for the enrichment argument and less support for the depletion argument.

\section{Goodness of Fit}

The Chi-square statistic for the model indicated a significant value. This implied that the model was not adequate. The Root Mean Square Error of Approximation (RMSEA) is a popular measure of fit and the model is deemed a good fit if the RMSEA value was less than 0.06. The RMSEA value for our model was 0.0553 - given the acceptable ranges, this implied that the model was a good fit. Brown and Cudeck (1993) suggested that the RMSEA was one of the most informative fit indices and it basically showed how well the model with optimally chosen parameter values would fit the population covariance matrix if it were available.

Two indices that use the information criteria were the Akaike Information Criterion (AIC) and the Consistent AIC (CAIC) indices. The AIC compensates or adjusts the model chisquare for model complexity while the CAIC adjusts the chi-square for both model complexity and sample size. The model AIC and CAIC values were lower than the corresponding numbers for the independent and the saturated models. These smaller values again indicated a better fit of the hypothesized model (Diamantopoulos and Siguaw, 2000). In addition, the information criteria required a sample size of at least 200 to make their application reliable. In our model, we met these criteria since our sample size was 322 .

Finally, fit indices compare the current model to an alternative model. Three of the fit indices, the Non-Normed Fit Index (NNFI), Comparative Fit Index (CFI) and Adjusted Goodness of Fit Index (AGFI), showed values of $0.851,0.861$ and 0.766 respectively. The CFI and AGFI indices should lie between 0 and 1 with values greater than 0.9 proving good fit of the model while slightly less than 0.9 showing acceptable fit of the model. The CFI and AGFI values for our model showed acceptable fit for the model. The NNFI value could be above 1 - again the NNFI value of 0.851 showed a good fit for our model. 


\section{Parameter Estimates}

Table 3 presents the standardized estimates of the measurement model while Table 4 presents the path coefficients to the model and Figure 2 presents a summary of standardized parameter estimates among the latent variables.

An examination of Table 3 reveals that relations between the latent variables and their respective indicators were large and statistically significant. Table 4 reveals that SIW and Positive Affect were positively and significantly related to well-being while Negative Affect was negatively and significantly related. WIS, Role-Overload and Role-Ease did not load in the path analysis significantly. The coefficient of determination $\left(R^{2}\right)$ for the entire path model was 0.56 , which indicated a substantial contribution of the six latent variables to the general well being of college students. Figure 2 shows that the residual for the entire model is 0.35 which indicated a relatively small amount of error caused by unknown exogenous variables. However, when measuring a theoretical 
Table 3

Standardized Maximum Likelihood Parameter Estimates

\begin{tabular}{|c|c|c|c|}
\hline PARAMETERS & ESTIMATES & PARAMETERS & ESTIMATES \\
\hline \multicolumn{2}{|c|}{ Well-Being } & \multicolumn{2}{|c|}{ Role-Ease } \\
\hline \multicolumn{2}{|c|}{ Emotional Well-being } & V69 & .754 \\
\hline V4 & .770 & V70 & .731 \\
\hline V2 & .717 & V67 & .697 \\
\hline V12 & .691 & V68 & .623 \\
\hline V8 & .668 & V71 & .619 \\
\hline V7 & .607 & \multicolumn{2}{|c|}{ Role-Conflict (WIS) } \\
\hline V3 & .589 & V21 & .553 \\
\hline V16 & .492 & V22 & .470 \\
\hline \multicolumn{2}{|c|}{ General Well-being } & V19 & 347 \\
\hline V1 & .723 & \multicolumn{2}{|c|}{ Role-Conflict (SIW) } \\
\hline V11 & .691 & V26 & .745 \\
\hline V6 & .571 & V25 & .711 \\
\hline V13 & .540 & V24 & .650 \\
\hline V17 & .497 & \multicolumn{2}{|c|}{ Positive Affect } \\
\hline \multicolumn{2}{|c|}{ Health } & V98 & .808 \\
\hline V10 & .826 & V105 & .799 \\
\hline V15 & .808 & V108 & .774 \\
\hline \multicolumn{2}{|c|}{ Role-Overload } & V106 & .768 \\
\hline V60 & .800 & V99 & .746 \\
\hline V63 & .761 & V103 & .731 \\
\hline V61 & .708 & V92 & .710 \\
\hline V64 & .684 & V101 & 691 \\
\hline V62 & .673 & V90 & .632 \\
\hline V66 & .621 & \multicolumn{2}{|c|}{ Negative Affect } \\
\hline V65 & .610 & V109 & .788 \\
\hline V59 & .567 & V96 & .774 \\
\hline & & V102 & .764 \\
\hline & & V95 & .691 \\
\hline & & V107 & .558 \\
\hline
\end{tabular}


Table 4

Standardized path Coefficients and Coefficients of Determination for combinations of Latent Variables $(n=322)$

\begin{tabular}{|l|c|c|c|c|c|c|c|}
\hline $\begin{array}{l}\text { Dependent } \\
\text { Variable }\end{array}$ & $\begin{array}{c}\text { Role } \\
\text { Overload }\end{array}$ & $\begin{array}{c}\text { Role } \\
\text { Ease }\end{array}$ & WIS & SIW & $\begin{array}{c}\text { Positive } \\
\text { Affect }\end{array}$ & $\begin{array}{c}\text { Negative } \\
\text { Affect }\end{array}$ & $\mathbf{R}^{2}$ \\
\hline Wellbeing & .15 & .15 & .10 & $.17^{\star \star}$ & $.27^{\star \star}$ & $-.39^{\star \star}$ & .56 \\
\hline $\begin{array}{l}\text { Role } \\
\text { Overload }\end{array}$ & & $.39^{\star \star}$ & $.47^{\star \star}$ & .06 & .06 & $-.14^{\star}$ & .71 \\
\hline Role Ease & & & $.37^{\star \star}$ & $.35^{\star \star}$ & -.03 & .05 & .39 \\
\hline WIS & & & $.52^{\star \star}$ & .03 & $-.16^{\star \star}$ & .33 \\
\hline SIW & & & & & $.26^{\star \star}$ & $-.21^{\star \star}$ & .10 \\
\hline $\begin{array}{l}\text { Positive } \\
\text { Affect }\end{array}$ & & & & & & $.09^{\star}$ & .01 \\
\hline
\end{tabular}

Note: ${ }^{\star \star}=p<.01,{ }^{*}=p<.05$

Figure 2

Summary of standardized parameters among the latent variables

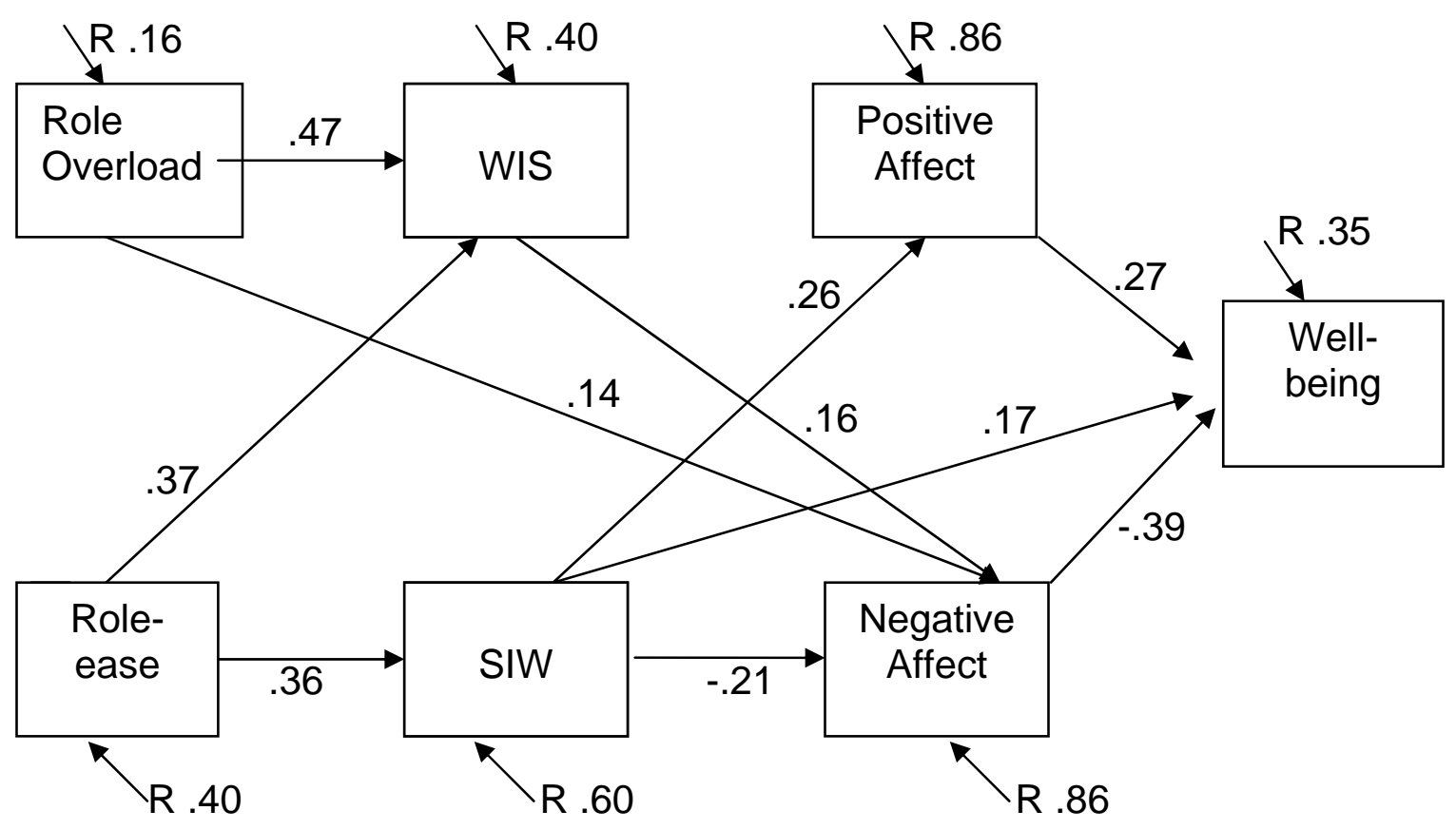


construct related to human emotions, one would expect high residuals since many variables that could effect emotions were unaccounted for in the model. Therefore, some of the residuals like those for positive and negative affect $(0.86)$ were relatively high.

The standardized path coefficients shown in Figure 2 lent support to both the enrichment and depletion arguments, depending on the type of role-balance (roleoverload or role-ease) experienced by the student. The path coefficients for Role-Ease, SIW, Positive Affect and Well-Being were significantly and positively associated in the expected temporal order. Although the path coefficient for Role-Ease was not directly related to Well-Being, it was significantly related to SIW, which in turn, had significant path coefficients to both Positive Affect and Well-Being. The path indicates that college students who engaged in multiple roles experienced role-ease. This is perceived as school interfering with work leading to increased positive affect and increased wellbeing. This scenario demonstrated the beneficial effects of engagement in multiple roles, and therefore supported the enrichment argument.

It is notable that there was no path through Positive Affect either directly or indirectly for Role-Overload. The path from Role-Overload to Well-Being either went directly through Negative Affect or through WIS and then through Negative Affect. Therefore, college students who experienced Role-Overload were likely to perceive work interfering with school which, in turn, increased the negative affect and reduced feelings of well-being. This scenario demonstrates the detrimental effects of engagement in multiple roles or the depletion argument.

\section{Discussion}

The cost of education is on the rise and universities, including business schools, are in a competitive market for qualified students. Many parents can no longer afford to pay for their children's entire education. Consequently, the student is put in a position of either getting a scholarship or finding paid work to supplement his or her expenses. This was the most common scenario in our sample of business school students. The findings in this study have similar implications for all institutions of higher learning. Students are experiencing increased demands on their time and the effect on their wellbeing must be a great concern for all university administrators.

This study developed and tested a conceptual model of work-school conflict and wellbeing. The entire sample was comprised of working students since students with such multiple roles were of the greatest interest in this research. Past research on multiple roles in the work/family relationship guided the theory because of the lack of theory and research on working students in this particular age group.

The depletion argument implied that opposing incompatible pressures from work and school were detrimental to an individual and that role participation evoked emotional strain. Past research had established that role-balance moderated this relationship (Barnett and Hyde, 2001; Buda and Lenaghan, 2005, Marks and MacDermid, 1996). 
The findings in this study lent some support to this position. When college students experienced role-overload (strain), the conflict they were likely to experience was work interfering with school which, in turn, increased negative affect and lowered a student's feelings of well-being. This finding suggests that students might find work as both instrumental and emotional in achieving their goal of acquiring a college education. However, this depended on the type of role-balance they experienced. Our research suggested that role-overload was more likely to be indirectly related to lower feelings of well-being than role-ease. Therefore, when college students experienced role-overload, it may begin a cognitive emotional chain of experiences that eventually reduced feelings of well-being.

In contrast, the enrichment argument suggested that opposing pressures from work and school roles could be beneficial to the individual. The conceptual model and measurement model both supported this argument. The hypothesized relationships for the conceptual model were all positive and significant and the path parameters under the condition or role-ease demonstrated support for the enrichment argument. The findings suggest that when college students experienced role-ease and the type of conflict they experienced was school interfering with work, positive affect was likely to increase and negative affect was likely to decrease which, in turn, lead to greater feelings of well-being. School interfering with work was perceived as a "good or beneficial" type of conflict by the college student (unlike family interfering with work for the adult worker) since the main objective for the typical student was to acquire a college degree. In our measurement model, both positive and negative affects were significantly related to well-being demonstrating support for the enrichment argument. Our measurement model demonstrated that role-balance was essential to well-being in students but like so many other variables in social science, it depended on which conditions they were experienced.

The above conclusions show that the results from the study were mixed concerning the two arguments, enrichment argument and depletion argument. Working students could have either a positive or a negative disposition towards the multiple roles about how the roles affect their wellbeing. It really depends on the individual student. A student may view the multiple roles as a positive influence because when they work while they are in school, they view the work as helping them in their studies through work-related experiences, internships etc. Such students perceive the work-related role as a positive factor in fulfilling their education related goals. On the other hand, a different student may view the conflict between the multiple roles from a totally opposite perspective and view it as a detrimental effect to fulfilling their education goals. The results clearly showed that this type of mixed outcomes of the multiple roles is probably more prevalent than the fact that one of the two arguments dominates over the other one.

The implications for this study center around two significant findings. The first implication is that for some students, well-being is likely to continue to decline since the cost of an undergraduate education is likely to continue to rise. This will put more pressure on students to work longer hours. As work related stressors continue to increase and if certain students perceive this as detrimental to their studies, feelings of 
well-being are likely to decrease. Wellbeing for such students should be a concern for all universities - therefore, attention should be paid to these phenomena. Perhaps academic counselors need to be involved in these students' employment decisions and make time management courses mandatory before they engage in paid work. In addition, universities should offer training opportunities to such students in an effort to prepare them for the challenges of managing work and school. Similar to the freshmen courses many institutions offer during the first semester, courses that focus on issues related to the transition from high school to college will support and educate such students who have assumed a meaningful work role and who feel this role is a threat to their wellbeing. The curriculum for such a course can include various aspects of developing resiliency and strategies to manage one's stress.

The second implication is that some students may find that engaging in work is an enriching experience. Working is not just an economic exchange. It provides an important social function as college students leave adolescence and enter adulthood. Therefore, for such students, perceptions of positive or negative work experiences may well be influenced by their social experiences at work as well as work stressors. As students work, they accrue specific work skills; acquire social and communication skills; the ability to function in teams; solve problems; make decisions; handle delicate situations with tact - all of these can enhance their self-esteem. Such students view work as an important step in advancing their careers. It may provide the necessary experience associated with many professional opportunities. If a student can engage in work that is career related, it has positive implications in terms of his/her confidence. It provides one with a feeling of direction and satisfaction; feelings often missing in the college senior who has not begun to think about a career yet. Universities need to explore the support given to education outside of the classroom. Certainly, opportunities for paid work can be viewed as such an endeavor. On-campus career centers need to bolster efforts towards securing internship opportunities that provide meaningful work experiences to students. Moreover, career center professionals must develop and nurture relationships with alumni to help secure internships and, equally as important, serve as mentors to working students.

Several limitations to this study need to be mentioned. First, our model was conceptualized in terms of causal relationships. We recognize that cross-sectional data did not allow us to draw causal inferences concerning the various relationships. However, the cross-sectional approach provided an efficient and economical way of assessing the utility and hypotheses of our model before engaging in more costly longitudinal research (Markel and Frone, 1998). Second, all the data were based on self-reports, increasing the likelihood that the size of the parameter estimates were inflated by common method bias. However, the use of self-report measures seemed logical since the study was interested in capturing stable, internal states of the respondents that could not be manipulated. Furthermore, research had failed to show evidence of any meaningful inflation due to self-report measures (Crampton and Wagner, 1994). Rothbard and Edwards (2003) justified the use of self-report measures when they were consistent with the focal constructs of the study since the most accurate source of information regarding an individual's own perceptions of work- 
student conflict and well-being would be the person himself/herself. Finally, the data were not obtained from a representative sample of all college students and, therefore, the generalizability of the present results may be limited. However, despite these potential methodological limitations, the results of this initial study suggest that additional research would be worthwhile. Our conceptual model would provide a useful beginning to the systematic study of work-school conflict and a student's well-being. Future longitudinal research using a more representative national sample would provide a much stronger test of the conceptual model used in this study.

\section{References}

Barnett, R.C., Gareis, K.C., James, J.B. \& Steele, J. (2003). Planning Ahead: College Seniors' Concerns About Career-Marriage Conflict. Journal of Vocational Behavior, 62(2), $305-319$.

Barnett, R.C. and Hyde, J.A. (2001). Women, Men, Work and Family: An Expansionist Theory. American Psychologist, 56, 781-796.

Barnett, R.C., Marshall, N.L. \& Pleck, J.H. (1992). Men's Multiple Roles and their Relationship to Men's Psychological Distress. Journal of Marriage and Family, 54, 358367.

Bartolome, F. \& Evans, P.A. (1979). Must Success Cost so Much? Harvard Business Review, 58, 137-148.

Browne M.W. \& Cudeck, R. (1993). Alternative Ways of Assessing Model Fit. In Testing Structural Equation Models. K.A. Bollen and J.S. Long. Newbury Park, CA: Sage. 445455.

Bruck, C. S. \& Allen, T.D. (2003). The Relationship Between Big Five Personality Traits, Negative Affectivity, Type A Behavior and Work-family Conflict. Journal of Vocational Behavior, 63, 457-472.

Buda, R. \& Lenaghan, J.A. (2005). Engagement in Multiple Roles: An Investigation of the Student-Work Relationship. The Journal of Behavioral and Applied Management, 6(3), 211-224.

Burke, R. J., Brief, A.P. \& George, J.M. (1993). The Role of Negative Affectivity in Understanding Relations Between Self-reports of Stressors and Strains: A Comment on the Applied Psychology Literature. Journal of Applied Psychology, 78(3), 402-12.

Burke, R.J. \& Weir, T. (1980). Type A Behavior, Occupational and Life Demands, Satisfaction, and Well-being. Journal of Human Stress, 6, 28-38. 
Burke, R.J. Weir, T. \& DuWors, R.E. (1979). Type A Behavior of Administrators and Wives' Reports of Marital Satisfaction and Well-being. Journal of Applied Psychology 64, 57-65.

Carlson, D. S. (1999). Personality and Role Variables as Predictors of Three Forms of Role Family Conflict. Journal of Vocational Behavior, 55, 236-253.

Chen, P. \& Spector, P. (1991). Negative Affectivity as the Underlying Cause of Correlations Between Stressors and Strains. Journal of Applied Psychology, 76, 398407.

Crampton, S. M. \& Wagner, J.A. (1994). Percept-Percept Inflation in MicroOrganizational Research: An Investigation of Prevalence and Effects. Journal of Applied Psychology, 79, 67-76.

Diamantopoulos, A. \& Siguaw, J.A. (2000). Introducing Lisrel: A Guide for the Uninitiated. Thousand Oaks, CA: Sage.

Dupuy, H. J. (1977). The general well-being schedule. In A concurrent Validational Study of the NCHCS' General Well-Being Schedule. Eds. A.F. Fazio, US Department of Health Resources Administration, 1-3.

Edwards, J. R. \& Rothbard, N.P. (2000). Mechanisms Linking Work and Family: Clarifying the Relationship Between Work and Family Constructs. Academy of Management Review, 25, 178-199.

Edwards, J.R. \& Rothbard, N.P. (1999). Work and Family Stress and Well-being: An Examination of Person Environment Fit in the Work and Family Domains. Organizational Behavior and Human Decision Processes, 77, 85-129.

Fazio, A. F. (1977). A concurrent validation study of the NCHS General Well-Being Schedule (Dept. of H. E. W. Publ. No. HRA-78-1347). Hyattsville, MD: National Center for Health Statistics.

Friedman, S. D. \& Greenhaus, J.H. (2000). Work and Family - Allies or Enemies? What happens when business professionals confront life choices? Oxford University Press.

Frone, M. R. (2003). Work-family balance. In Handbook of Occupational Health Psychology. J. C. Quick and L. E. Tetrick. Washington, DC: American Psychological Association. 143-162.

Frone, M.R., Russell, M. \& Cooper, M.L. (1997). Relation of Work-family Conflict to Health Outcomes; A Four-Year Longitudinal Study of Employed Parents. Journal of Occupational and Organizational Psychology 70, 325-335.

George, J. (1989). Mood \&Absence. Journal of Applied Psychology 74, 317-24. 
Goode, W. J. (1960). A Theory of Role Strain. American Sociological Review, 25, 483496.

Greenhaus, J. H. \& Beutell, N.J. (1985). Sources of Conflict Between Work \&Family Roles. Academy of Management Review 10, 76-88.

Greenhaus, J.H. \& Parasuraman, S. (1986). A Work-Nonwork Interactive Perspective of Stress \&lts Consequences. Journal of Organizational Behavior Management 8, 3760.

Greenhaus, J.H. \& Powell, G.N. (2006). When Work \& Family Are Allies A Theory Of Work-Family Enrichment. Academy of Management Review 31, 72-92.

Greenhaus, J.H., Allen, T. D., \& Spector, P. E. (2006). Health consequences of workfamily conflict The dark side of the work-family interface. In Research in occupational stress \&well-being. Eds. P. L. Perrewe \&D. C. Ganster. Amsterdam Elsevier, pp. 61-98.

Grzywacz, J. G., Almeida, D.M. \& McDonald, D.A. (2002). Work-family Spillover \& Daily Reports of Work \&Family Stress in the Adult Labor Force. Family Relations 51, 28-36.

Hammer, L. B., Cullen, J.C., Caubet, A., Johnson, J., Neal, M.B. \& Sinclair, R.R. (2002). The Effects of Work-family Fit on Depression A Longitudinal Study. Paper Presented at the 117th Annual Meeting of SIOP, Toronto.

Hanson, G. C., Colton, C.L. \& Hammer, L.B. (2003). Development \&Validation of a Multidimensional Scale of Work-family Positive Spillover. Paper presented at the $118^{\text {th }}$ Annual Meeting of SIOP, Orlando.

Higgins, C. A. \& Duxbury, L.E. (1992). Work-family Conflict A Comparison of Dual Career \&Traditional Career Men. Journal of Organizational Behavior, 13, 389-411.

Higgins, C.A., Duxbury, L.E. \& Irving, R.H. (1992). Work-family Conflict in the DualCareer Family. Organizational Behavior \&Human Decision Process, 51, 51-75.

Joreskog, K. \& Sorbom, D. (1986). Lisrel 8.3 Analysis of Linear Structural Relationships by Maximum Likelihood and Least Squares Methods. Mooresville IN Scientific Software.

Kahn, R., Wolfe, D.M., Quinn, R.P., Snoek, J.D. \& Rosenthal, R.A. (1964). Organizational Stress Studies in Role Conflict and Ambiguity. New York, NY Wiley.

Karatzias, A., Chouliara,Z., Power, K. \& Swanson, V. (2006). Predicting general wellbeing from self-esteem \&affectivity An exploratory study with Scottish adolescents. Journal of Quality of Life Research, 15(7), 1121-1196. 
Kopelman, R. E., Greenhaus, J.H. \& Connolly, T.F. (1983). A Model of Work, Family \&Interrole Conflict A Construct Validation Study. Organizational Behavior \&Human Performance, 32, 198-215.

Lightdale, J. R. \& Prentice, D.A. (1994). Rethinking Sex Differences in Aggression Aggressive Behavior in the Absence of Social Roles. Personality \&Social Psychology Bulletin, 20, 30-44.

Lobel, S.A. (1991). Allocation of Investment in Work \&Family Roles Alternative Theories \& Implications for Research. Academy of Management Review, 16, 507-21.

Lucas, R. \& Lammont, N. (1998). Combining Work \&Study An Empirical Study of Fulltime Students in School, College \&University. Journal of Education \&Work, 11, 41-56.

Markel, K. S. \& Frone, M.R. (1998). Job Characteristics, Work-school Conflict \&School Outcomes Among Adolescents Testing a Structural Model. Journal of Applied Psychology, 83(2), 77-287.

Marks, S. R. (1977). Multiple Roles \&Role Strain Some Notes on Human Energy, Time and Commitment. American Sociological Review, 42, 921-936.

Marks, S.R. \& MacDermid, S.M. (1996). Multiple Roles \&the Self A Theory of Role Balance. Journal of Marriage \& Family, 58, 417-432.

Martin, T. N. \& Schermerhorn, J.R. (1983). Work and nonwork Influences on Health A Research Agenda Using Inability to Leave as a Critical Variable. Academy of Management Review, 8, 650-659.

McDowell, I. \& Newell, C. (1987). The general well-being schedule. In Measuring Health A Guide to Rating Scales \&Questionnaires. Eds I. McDowell \&C. Newell. Oxford University Press, 125-132.

Netemeyer, R.G., Boles, J.S. \& McMurrian, R. (1996). Development \&Validation of Work-Family Conflict \&Family-work Conflict Scales. Journal of Applied Psychology, 81, 400-410.

Parasuraman, S., Purohit, Y.S., Godshalk, V.M. \& Beutell, N.J. (1996). Work \&Family Variables, Entrepreneurial Career Success, and Psychological Well-Being. Journal of Vocational Behavior, 48, 275-300.

Pedhazur, E.J. \& Schmelkin, L.P. (1991). Measurement, Design, \&Analysis An Integrated Approach. Hillsdale, NJ Erlbaum.

Pleck, J. H., Staines, G.L. \& Lang, L. (1980). Conflicts Between Work \& Family Life. Monthly Labor Review, 103, 29-32. 
Repetti, R. L. (1987). Linkages Between Work \& Family Roles. Applied Social Psychology Annual, 7, 98-127.

Rothbard, N. P. (2001). Enriching or Depleting? The Dynamics of Engagement in Work \& Family Roles. Administrative Science Quarterly, 46, 655-68.

Rothbard, N.P. \& Edwards, J.R. (2003). Investment in Work \&Family Roles A Test of Identity \& Utilitarian Motives. Personnel Psychology, 56, 699-730.

Ruderman, M. N., Ohlott, P.J., Panzer, K. \& King, S.N. (2002). Benefits of Multiple Roles for Managerial Women. Academy of Management Journal, 45, 369-386.

Stoeva, A. Z., Chiu, R.K. \& Greenhaus, J.H. (2002). Negativity Affectivity, Role Stress \& Work-family Conflict. Journal of Vocational Behavior, 60, 1-16.

Svavarsdottir, E.K. \& Rayens, M.K. (2005). Hardiness in families of young children with asthma. Journal of Advanced Nursing, 50(4), 381-390.

Tellegen, A. (1985). Structure of Mood \&Personality \&Their Relevance to Assessing Anxiety, with an Emphasis on Self Report. In Anxiety \&The Anxiety Disorders. Eds. A. H. Tuma \&J. D. Maser. Hillsdale, NJ Erlbaum. pp. 681-706.

Voydanoff, P. (2001). Incorporating community into work \&family research A review of basic relationships. Human Relations, 54, 1609-1637.

Watson, D., Clark, L. A. \& Tellegen, A. (1988). Development \&Validation of Brief Measures of Positive \&Negative Affect the PANAS Scales. Journal of Personality \& Social Psychology, 54, 1063-1070.

Watson, D. \& Pennebaker, J. (1989). Health Complaints, Stress, \&Distress Exploring the Central Role of Negative Affectivity. Psychological Review, 96, 234-54.

Watson, D. \& Tellegen, A. (1985). Toward a Consensual Structure of Mood. Psychological Bulletin, 98, 219-235. 